\title{
Evaluation of Distribution System Reliability Indices Using Fuzzy Reasoning Approach
}

\author{
A. Paci, R. Bualoti, and M. Çelo
}

\begin{abstract}
The most fundamental problems in the distribution system are the quality, the continuity, and the power supply. Political and economic changes were accompanied by changes in the structure of the electric load in the distribution network. Lack of investment and aging of the distribution company assets was accompanied by a decrease in the reliability of the distribution system. Identification and classification of assets from the point of view of their maintenance and replacement was one of the problems that were posed to the engineers. Fuzzy logic can be successfully used to evaluate distribution system reliability indices. In this paper fuzzy logic is used to evaluate the distribution system reliability indices of lines and transformers using six input variables. These variables considered the most important are: Age, Operation, Maintenance, Electrical current loading, Exposure and Weather conditions (Wind or Temperature). The fuzzy inferences knowledge-based IF-THEN rule is developed using Matlab Fuzzy software. The detailed analysis of the fuzzy system surfaces shows that the factors taken in consideration are dynamically and accurately connected to each other. The constructed rules based in engineering experience accurately represent the Reliability Indices.
\end{abstract}

Index Terms - Fuzzy Reasoning, Distribution System, Reliability Indices, System Reliability. Failure Rate, Interruption Rate.

\section{INTRODUCTION}

The distribution system reliability is an area that is gaining great importance. Grid development (long-term), Asset management (AM) (mid-term) and System operation (shortterm) are the main activities of power system reliability specialists [1]. In the past, the three processes were considered as separate activities. The distribution system now focuses on improving performance while achieving greater customer satisfaction while ensuring that the costs of operating the grid are kept under control.

Asset Management is the combination of management, financial, economic and engineering applied to physical assets of power system with the objective of providing the required level of service in the most cost-effective manner [2]. In [3] the asset management is classified in different processes. The maintenance forms the crucial part of it. Traditional annual maintenance planning has the problem of excessive or insufficient maintenance.

The paper is organized as follows: Section 2 describes the distribution system reliability indices and Albanian
Distribution System; application of the proposed fuzzy approach is described in Section 3. The conclusions at the end of the paper describe the advantages of the developed system.

\section{DISTRIBUTION SYSTEM RELIABILITY INDICES}

Reliability assessment helps to identify weaknesses in terms of frequency of defects and duration of system failure. IEEE-P1366 lists several important definitions for reliability including what are momentary interruptions, momentary interruption events, and sustained interruptions quality. The indices can be divided into two categories: system indicators such and customer indicators.

The parameters that can be used in calculating the reliability according to the standard IEEE reliability indices [4] are SAIFI (System Average Interruption Frequency Index), SAIDI (System Interruption Period Length and CAIDI (Average Customer Interruption Duration Index), MAIFI (Momentary Average Interruption Frequency Index). Such indices are usually calculated based on historical data and probabilistic method. Various computational models and optimization techniques have been developed for maintenance, refurbishment, ageing, and monitoring techniques in asset management, like state diagram [5], fuzzy technique [6]-[8], ANN [9], PSO [10], linear programming, and optimization techniques [11].

\section{Albanian Distribution System}

Electric Distribution System Operator (EDSO) includes all network elements at voltage levels of $35,20,10,6,0.4 \mathrm{kV}$ as well as substations that make transformations from $110 \mathrm{kV}$ to them. The distribution system is managed by the company EDSO, which is $100 \%$ state-owned. The main function of EDSO is to provide electricity through the distribution network to all types of customers connected to this network. Its function is also the sale / purchase of energy in order to meet customer requirements and also the maintenance and further development of the network. Electric Distribution System Operator is organized in 11 distribution zones and 42 agencies [12].

The new social-economical developments change the electricity consumption [13] in Albania. In Fig. 1 is shown the structures of electricity consumption in two different years.

M. Çelo, Polytechnic University of Tirana, Albania. (e-mail: celomarialis ${ }^{\circledR}$ yahoo.com)
Submitted on December 09, 2020

Published on May 04, 2021

A. Paci, National Institute of Standards and Technology, Albania.

(e-mail: alekspaci@yahoo.it)

R. Bualoti, Polytechnic University of Tirana, Albania.

(corresponding e-mail: bualoti@gmail.com). 


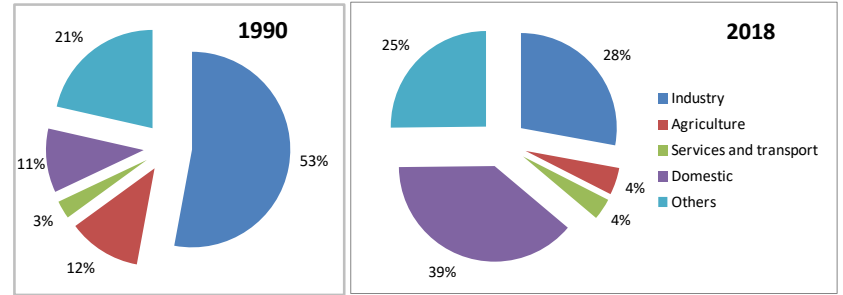

Fig. 1. The structures of electricity consumption in two different years.

In Fig. 2 is shown the electric energy consumed in the Distribution Regions of EDSO. It can be seen that about 50\% of the total energy consumption of electric distribution network is concentrated in the regions of Tirana and Durres.

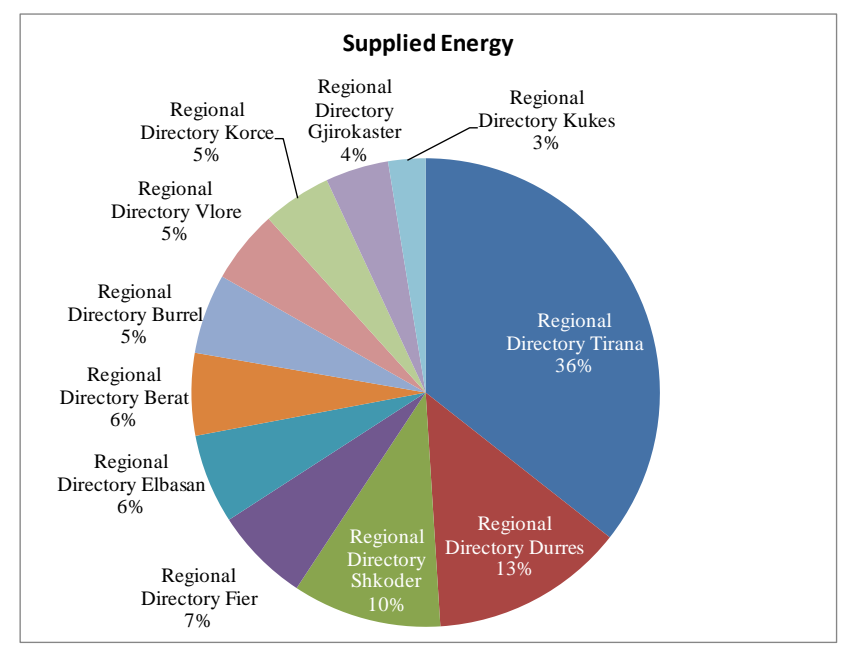

Fig. 2. The electric energy consumed in the electric distribution network by Distribution Regions for year 2018.

Electric Distribution System Operator manages 102 substations and about $16,350 \mathrm{~km}$ lines that stretches across the country. Capacity and mean age of transformers are shown on Fig. 3, while length of MV grid and mean age are shown on Fig. 4. The high degree of the deterioration of distribution assets is mainly due to their ages, (between 35 to 50 years), lack of investment and periodic maintenance [14].

Albanian distribution network has faced difficulties in managing the network, which are reflected in the quality of customer supply: the number of outages and their duration. After a restructuring process, it is focused on management and administration policies.

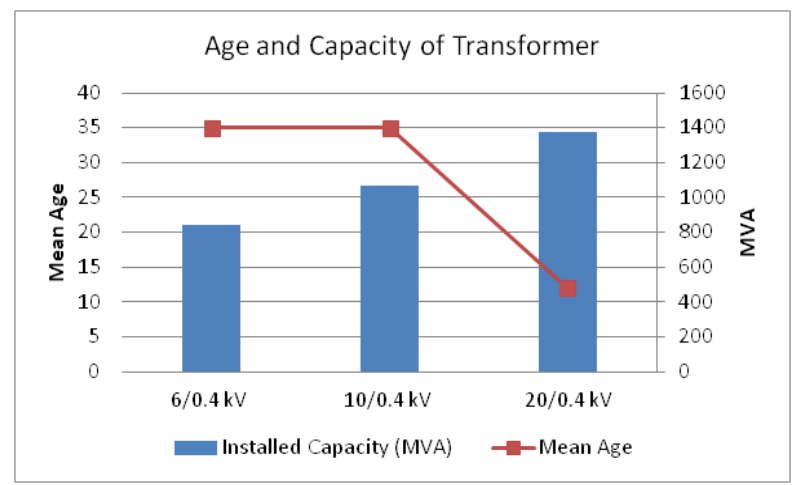

Fig. 3. The capacity and mean age of transformers.

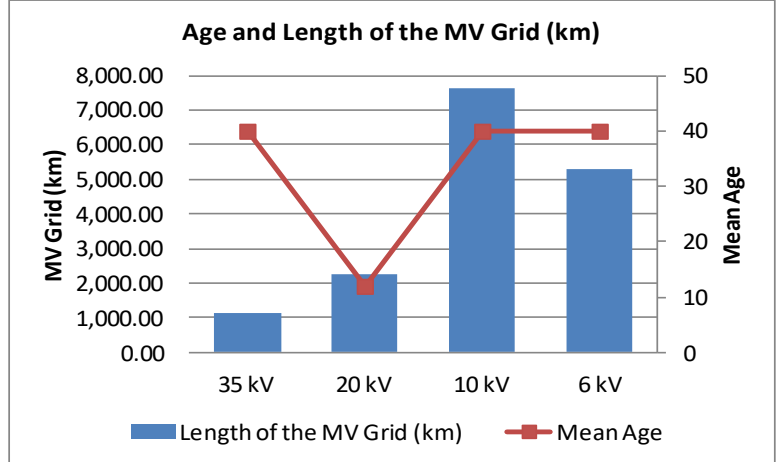

Fig. 4. The length and mean age of MV grid.

In previous work [15] it was discussed the result of a study in respect of the estimation of reliability indices and suggested recommendations on improving the reliability of the distribution system in Albania. Such methods depend on adequate and accurate archived database that in practice are usually unavailable or inaccurate.

Since the human experts play an important role in distribution system reliability evaluation, an approach based on fuzzy set theory is proposed to take the heuristic rules and operators' experience into account in the process of reliability indices evaluation.

In [16], authors utilized fuzzy methods to handle uncertainties and improve system reliability planning. In [17] several factors like age, exposure and wind for weather condition are modeled using fuzzy logic to evaluate the failure rate of the components in a distribution system. In this paper, a fuzzy approach is applied to model the additional uncertainty like, the effect of operation loading condition, annual maintenance planning and overvoltage which are the reasons for the failure of line and transformers and are not considered in the fuzzy modeling in [17]. In the proposed method, a fuzzy inference knowledge-based IF-THEN rule is developed adding three other inputs variables like operation loading conditions, maintenance, and temperature. In this study, the age of component, weather conditions, and exposure to risk are taken into account as well.

\section{THE PROPOSED FUZZY APPROACH}

Fuzzy sets and fuzzy logic have acquired great attention from researchers since their development. The fuzzy reasoning approach involves following steps:

1. Compile the heuristic rules.

2. Perform fuzzy reasoning.

Similar to ideas developed by [17] the fuzzy membership functions of three influential variables (the age of component, weather conditions, and the exposure to the risk) are modified to reflect better the impact on failure rate and average repair time of each component. Three other variables like operation loading conditions, maintenance and temperature are added. The framework of fuzzy approach is shown on Fig. 5. The next step in the methodology was to decide which includes in membership function design and fuzzy rules design. The crisp norms of transformers and lines of Distribution system were collected and transformed to fuzzy linguistic variables. Due to uncertainty an overlap between two consecutive variables is apply. 


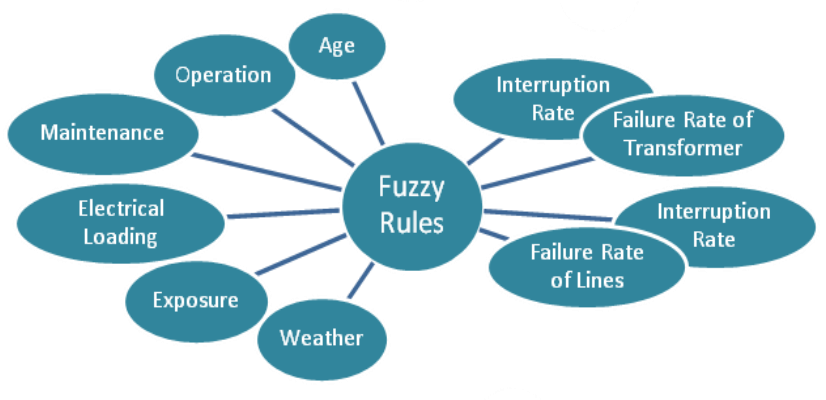

Fig. 5. The framework of fuzzy approach.

According to a survey taken with experience engineers of distribution system, fuzzy rules are constructed using the diagnostic rules to obtain the final decisions based on knowledge-based rules.

\section{A. The distribution Network Elements}

The lifetime of distribution network elements is estimated between 35 to 50 years under regular periodical maintenance and normal operation condition. The main components of electric distribution systems are distribution lines and transformers.

Distribution transformers have an average expected lifetime of 35 years. Typical lifetime of power transformer can go to 40-50 years. The insulation life is affected by the transformer loading, ambient temperature, the moisture, and the oxygen content of the oil. It determined mainly the lifetime of a distribution transformer [18].

Distribution lines have the average rate of amortization of about $2.1 \%$ per year. The cable insulation thermal degradation degree is depending on temperature. The cable temperature has a trend of change because of the season loading. During the period there was building heating the temperature increase cyclic exponential trend appears. According to insulation aging model, cable insulation operation life reduction is about $20 \%$ for temperature increase between $1{ }^{\circ} \mathrm{C}$ and $2{ }^{\circ} \mathrm{C}$ over normal [19]. So, a significant influence on operation life reduction of distribution lines has the thermal deterioration of insulating material.

In Fig. 6, there is shown the proposed FIS editor of MATLAB Fuzzy Logic Toolbox to evaluate both Line and transformer the Failure and Interruption Rate.

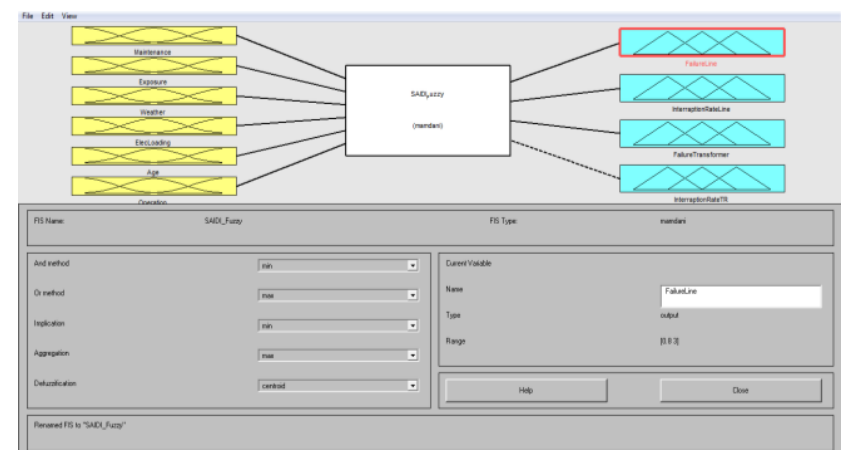

Fig. 6. Fuzzy Logic for the Reliability Indices using MATLAB.

\section{B. The input Fuzzy Membership Functions}

We have identified six factors of environmental or humanmade reasons that may affect the outage time and failure rate of line and transformers. These six variables are taken in consideration as fuzzy logic inputs. These variables considered the most important are: Age, Operation, Maintenance, Electrical current loading, Exposure and Weather conditions (Wind or Temperature). In following it will be presented fuzzy model for each variable.

1. Age

The failure rate rises when distribution assets get older. In the Bathtub curve are three phases of product life. Infant Mortality: these failures characterized a very early in life and quickly pass to a very low failure rate. Use Life: These failures are affected by variability in use and environment. Wear-out: These failure modes are predictable. The fuzzy membership of age is shown in Table VI and is design with four linguistic variables defined as infantile between 0 to 2 years, young between 0 to 8 years, middle-aged between 6 to 22 years, and old is between 20 to 35 .

\section{Operation}

Operational experience refers to the average number of defects reported in an established year. In this study, the number of defects reported is considered based in [20] where it was evaluated the faulted indexes per year and per $100 \mathrm{~km}$ line, as well as the mean duration time of repair calculated for a period of 15 years (Table I).

Based on faulted indexes the fuzzy membership of operation experience is design with two linguistic variables are defined as normal between 0 to 2 number of defects, and heavy which ranges between 1 to 5 as is shown in Table VI. We can use the same fuzzy membership of operation experience also for transformers.

TABLE I: THE MEAN DURATION TIME OF REPAIR

\begin{tabular}{ccc}
\hline \hline Vn of lines $[\mathrm{kV}]$ & $\begin{array}{c}\text { The faulted } \\
\text { indices }\end{array}$ & The repair hour \\
\hline $35 \mathrm{kV}$ with pendant isolator & $0.8-1$ & $8-10$ \\
$35 \mathrm{kV}$ with state isolator & $1-1.5$ & $4-6$ \\
6-10 kV & 3.5 & $4-6$ \\
Cable 6-10 kV & 2.4 & $10-15$ \\
\hline \hline
\end{tabular}

\section{Maintenance}

In [11] is discussed the maintenance management of distribution system assets. Traditional annual maintenance planning based mostly on old convention and subjective experience, having the problem of excessive or insufficient maintenance. The preventative maintenance procedure provides the service life prolongations of critical assets (Fig. 7) the increase of asset availability and avoids a major failure [21].

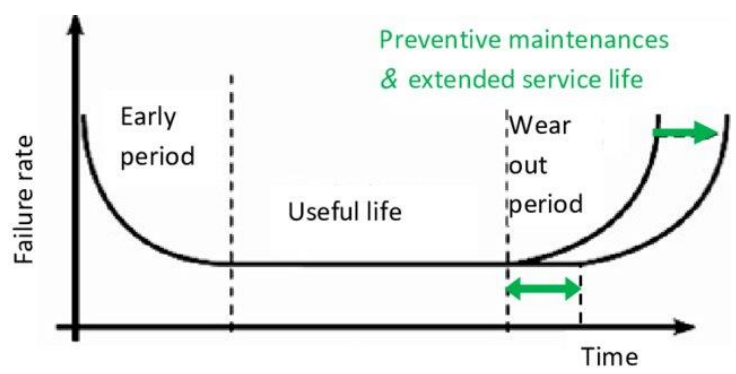

Fig. 7. The service life prolongations

The fuzzy membership of maintenance is shown in Table VI. Three linguistic variables are defined as No maintenance, except the very basic and mandatory actions, Light maintenance: basic maintenance, Heavy maintenance: midlife refurbishment - after 15 to 30 years in service 
(depending on the equipment status evaluation index).

Based on asset maintenance management the linguistic variables are defined according to the bathtub curve as No maintenance the assets between 0 to 8 years old of, Light between 6 to 24 year old of assets and Heavy which are older than 22 year.

\section{Electrical Current Loading}

The seasonal variation of temperatures and load has to consider in degradation under electro-thermal stress. Albanian distribution systems encounter a very rapid increase in load and as a result of financial constraints had to work in heavy load situations. Heavy load is an important factor as the condition worsens exponentially when the asset is overloaded. Fig. 8 represents the impact of heavy load on failure rate of transformers insulation [22].

The fuzzy membership of Electrical current loading is shown in Table VI and the three linguistic variables are defined as under load between 0 to $70 \%$, Normal which ranges between $50 \%$ to $130 \%$, and heavy load which ranges over $110 \%$.

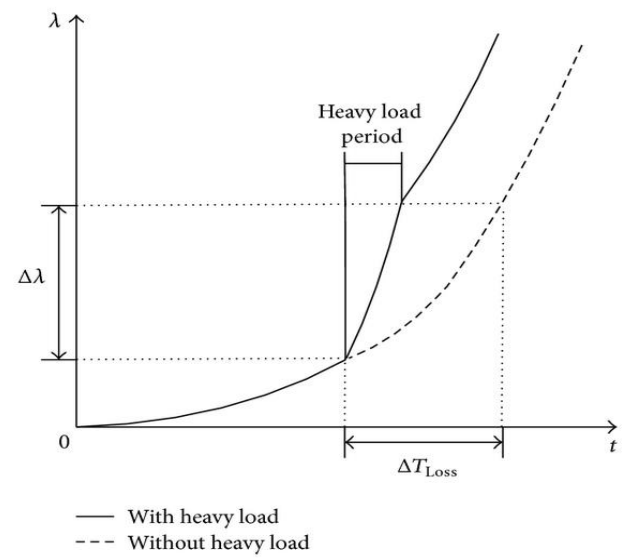

Fig. 8. The transformers insulation failure rate on heavy load conditions [22].

\section{Exposure}

Overhead line is exposed to fail by several reasons, like trees in the line path, mountainous area, and birds. The cables' exposure to the risk in developing urban area where during work in new construction often associated with damage to the cable network. The failure rate and outage time could be affected by these conditions.

The exposure of the line is estimated by percentage where the exposure low is considered till $40 \%$, average between $20 \%$ to $80 \%$ and high after $60 \%$.

The insulation life determined the lifetime of a transformer. The exposure of the transformer is estimated by amount of moisture in the oil where the exposure low is considered till $40 \%$, average between $20 \%$ to $80 \%$ and high after $60 \%$.

The fuzzy membership of exposure is shown in Table VI.

\section{Weather Condition}

The weather conditions are strongly relevant to the failure rate and outage time. Weather condition refers to the impact of the environment that surrounds have to the asset. A proper representative of weather conditions for distribution line is wind speed. Meantime, a proper representative of weather conditions for distribution transformer is temperature. The lifetime of a distribution transformer is mainly determined by insulation life [23] and the dominated factor ambient temperature. Reference [24] used a standardized engineering approach according to IEEE Standard C57.91.

The failure rate is less, and repair time is shorter when the weather condition is normal, in compared with an adverse weather condition [17]. The input fuzzy model of weather condition has two variables: normal and adverse weather conditions.

The fuzzy membership functions for distribution line, the wind speed of 0 to $60 \mathrm{~km} / \mathrm{h}$ is considered normal, and the wind speed is at the intervals of $40 \mathrm{~km} / \mathrm{h}$ to $100 \mathrm{~km} / \mathrm{h}$ is considered adverse. Referring to $60 \mathrm{~km} / \mathrm{h}$ the fuzzy membership functions can be express for distribution line the wind speed of 0 to 1 is considered normal and the wind speed is at the intervals of $2 / 3$ to $5 / 3$ is considered adverse.

The fuzzy membership functions for distribution transformer, the ambient temperatures of 0 to 30 degree are considered normal and the ambient temperatures is at the intervals of 20 to 50 degree is considered adverse. Referring to 30 degree the fuzzy membership functions can be express for distribution transformer the wind speed of 0 to 1 is considered normal and the wind speed is at the intervals of $2 / 3$ to $5 / 3$ is considered adverse.

\section{The Output Fuzzy Membership Functions}

We will use failure rate and average outage time as output variables for evaluated the reliability of lines and transformers. In Table VI are shown the membership functions for the proposed Fuzzy Approach.

\section{Failure Rate of Line}

The membership function of line failure rate is designed with five linguistic variables as has been shown in Table II.

TABLE II: THE LINGUISTIC VARIABLES OF FAILURE RATE

\begin{tabular}{cc}
\hline \hline The linguistic variables & The range \\
\hline Very Low & $0.8-1.2$ \\
Low & $1.1-1.5$ \\
Average & $1.4-2.0$ \\
High & $1.9-2.5$ \\
Very High & $2.4-3$ \\
\hline \hline
\end{tabular}

\section{Interruption Rate of Line}

The line interruption rate is represented by the average repairing time in hours. In Table III are shown four linguistic variables that represent the fuzzy membership function of line interruption rate.

TABLE III: THE LINGUISTIC VARIABLES OF INTERRUPTION RATE OF LINE

\begin{tabular}{cc}
\hline \hline The linguistic variables & The range of repairing time hours \\
\hline Good & $4-6$ \\
Suitable & $5-9$ \\
Bad & $7-15$ \\
Very Bad & $12-20$ \\
\hline \hline
\end{tabular}

\section{Failure Rate of Transformer}

The membership function of transformer failure rate is designed according [25] with five linguistic variables as has been shown in Table IV.

TABLE IV: THE LINGUISTIC VARIABLES OF TRANSFORMER FAILURE RATE

\begin{tabular}{cc}
\hline The linguistic variables & The range \\
\hline Very Low & $0.8-1.2$ \\
Low & $1.1-1.5$ \\
Average & $1.3-1.7$ \\
High & $1.6-2.2$ \\
Very High & $1.9-2.5$ \\
\hline \hline
\end{tabular}




\section{Interruption Rate of Transformer}

The transformer interruption rate is represented by the average repairing time in hours which is significantly higher that the line repairing time. Three linguistic variables that represent the fuzzy membership function of transformer interruption rate are shown in Table $\mathrm{V}$.
TABLE V: THE LINGUISTIC VARIABLES OF INTERRUPTION RATE OF TRANSFORMER

\begin{tabular}{cc}
\hline \hline The linguistic variables & The range of repairing time hours \\
\hline Good & $4-60$ \\
Suitable & $50-150$ \\
Very Bad & $120-200$ \\
\hline \hline
\end{tabular}

TABLE VI: THE MEMBERSHIP FUNCTIONS FOR THE PROPOSED FUZZY APPROACH Fuzzy Input

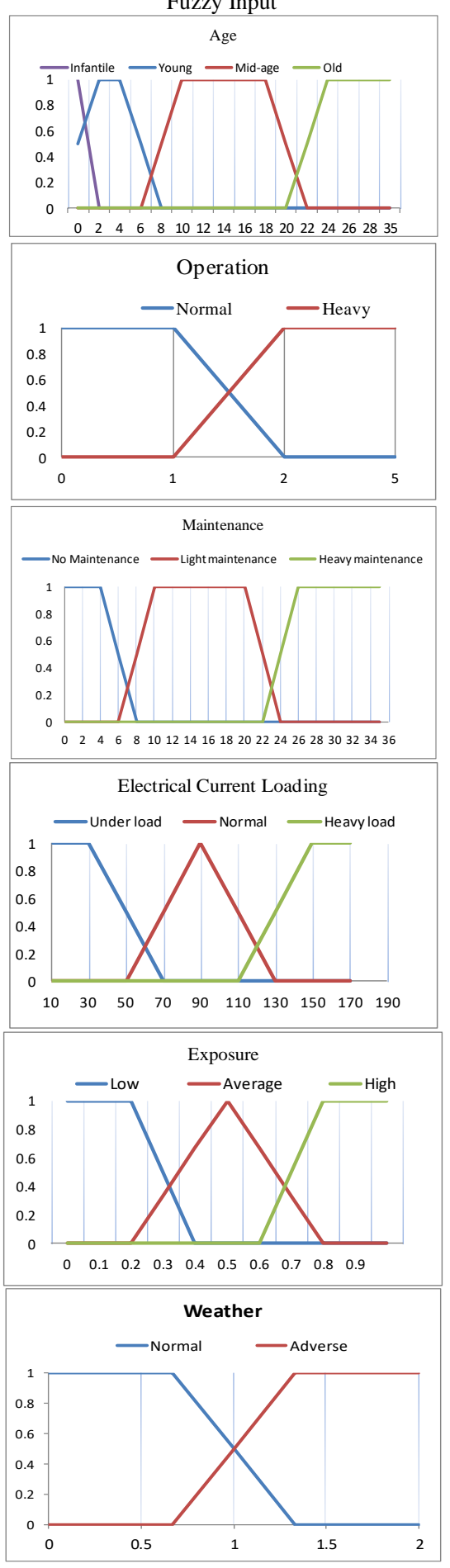

If Then Rules

Fuzzy Rules
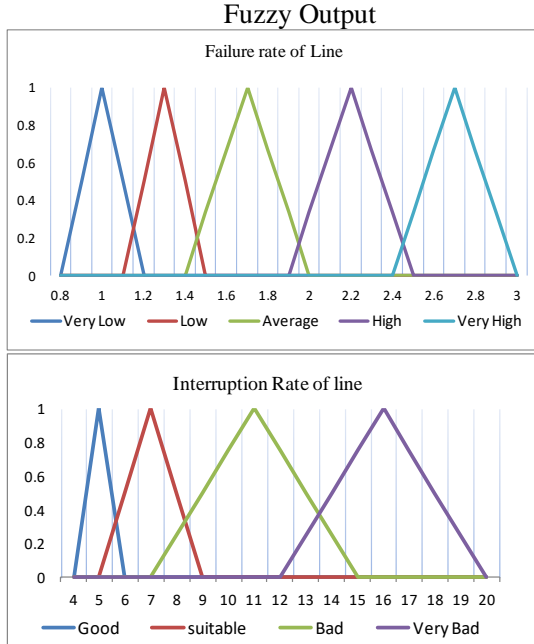

Failure rate of Transformer

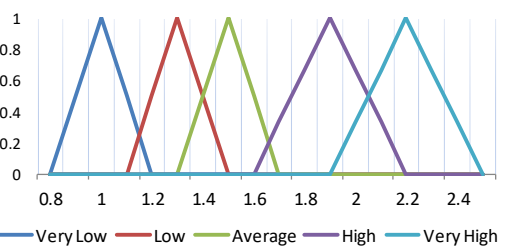

— Very Low — Low —Average — High — Very High

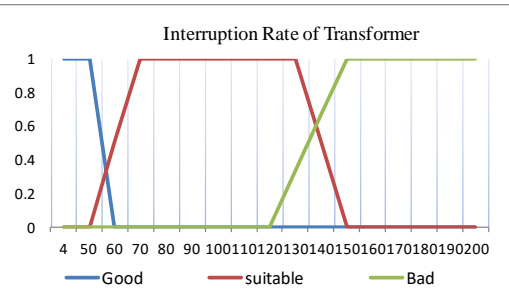

\section{APPLICATION OF THE PROPOSED FUZZY APPROACH}

In the proposed method, a fuzzy knowledge-based approach is developed. To define the fuzzy inference rules the following steps are taken:

1. Define the total numbers of interactions between the input output variables.

2. Exclude the rules of illogical relations.

3. The output for each rule was determined by the experience engineers of Distribution Company.

In the last step of the methodology, the fuzzy logic toolbox of MATLAB was applied to entering the membership functions and fuzzy rules. Furthermore, the software helped 
to automate the evaluation of both Line and transformer the Failure and Interruption Rate and to analyze the output performance.

This section shows the results of applying the method and discusses the results obtained. In Fuzzy Reliability approach, we initially applied a total of 11 fuzzy inference rules and further 21 fuzzy inference rules.

Each rule consists of two components which are the antecedent (IF part) and the consequent (THEN part).

With the fuzzy logic technique, partial output membership can be improved by increasing the number of rules. In the defuzzification process of fuzzy approach we have used the Centroid and Bisector methods.
For the fuzzy logic control, Mamdani's Max-Min composition technique is used. FIS derives output fuzzy sets from judging all the fuzzy rules by finding the weighted average of all 21 fuzzy rules output.

Fig. 9 represents the influence of different factors to the Fuzzy Reliability Indices method.

The detailed analysis of the fuzzy system surfaces shows that the factors are dynamically and accurately connected to each other. The surfaces reflect the accuracy of the constructed rules. The proposed Fuzzy model can be used to evaluate Reliability Indices. Fuzzy output is given by rule viewer of FIS. Fig. 10 represents the result influence of different factors to the Fuzzy Reliability Indices method.

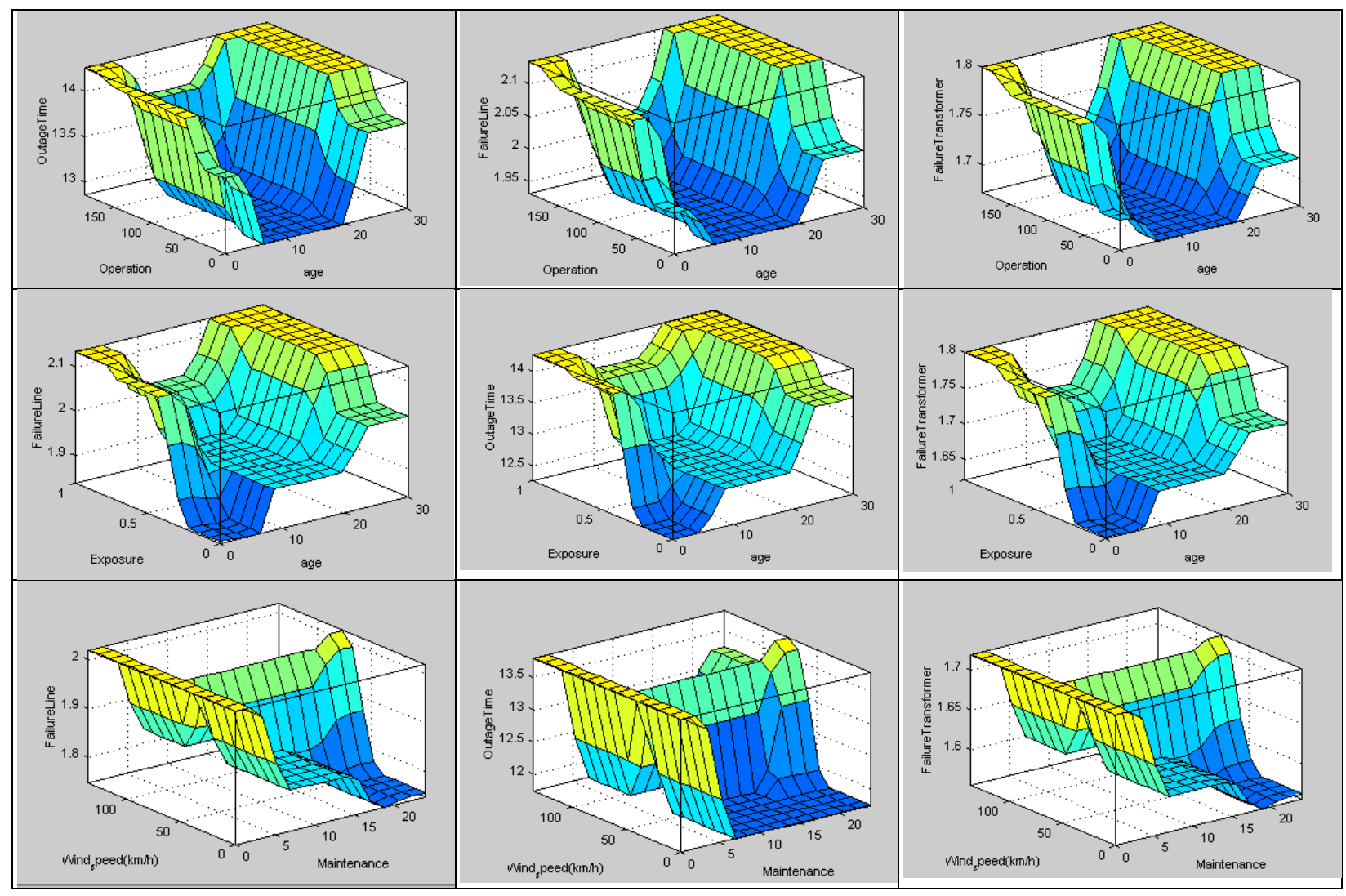

Fig. 9. The influence of different factors to the Fuzzy Reliability Indices method.

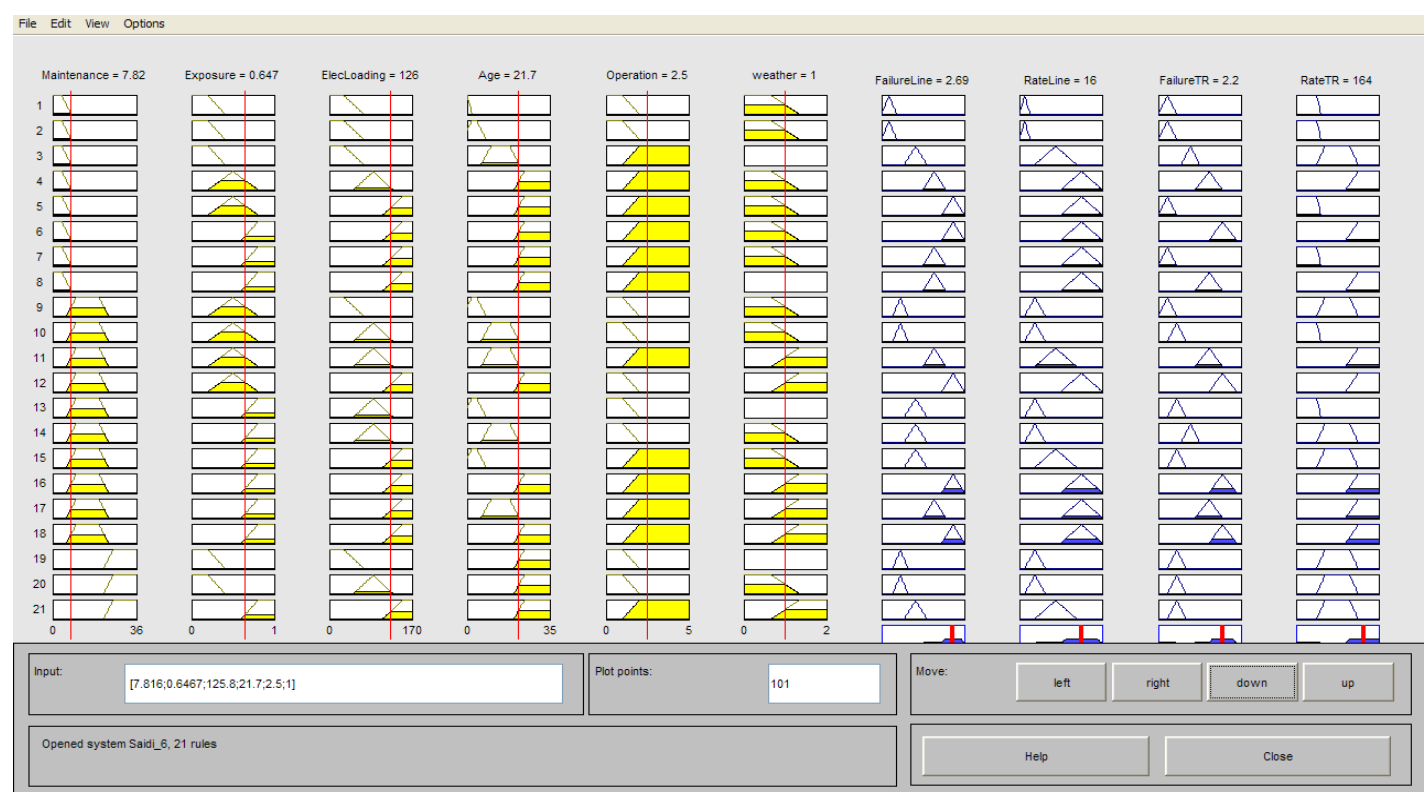

Fig. 10. Fuzzy inference rules for the Reliability Indices. 


\section{CONCLUSION}

The use of Fuzzy methodology gives us the opportunity to determine Reliability Indices for a certain maintenance plan and thus the possibility of comparing different plan in order to obtain the optimal maintenance strategy and optimal outage plan.

The detailed analysis of the fuzzy system surfaces shows that the factors taken in consideration are dynamically and accurately connected to each other. The constructed rules based in engineering experience accurately represent the Reliability Indices. The application in our power system has proved the accuracy of the proposed methodology.

As a conclusion, it was found that the use of Fuzzy methodology ensures the consideration of engineering experience which is very important in solving system problems. The use of Fuzzy methodology provides the possibility of finding Reliability Indices.

\section{REFERENCES}

[1] S. R. Khuntia, B. W. Tuinema, J. L. Rueda, \& van der Meijden, M. A. M. M. (2016). Time-horizons in the planning and operation of transmission networks: An overview. IET Generation, Transmission and Distribution, 10(4), 841-848. https://doi.org/10.1049/ietgtd.2015.0791.

[2] J.J. Smit, B. Quak, E. Gulski, "Integral decision support for asset management of electrical infrastructures". Proc. of IEEE Systems, Man, and Cybernetics Conf., 2006.

[3] CIGRE WG C1.25, Asset Management Decision Making using different Risk Assessment Methodologies, Technical Brochure 541, June 2013.

[4] IEEE Guide for Electric Power Distribution Reliability Indices, IEEE Standard 1366, 2003 Edition.

[5] S.K. Abeygunawardane, P. Jirutitijaroen, "A realistic maintenance model based on a new state diagram". Proc. of Int. Conf. on Probabilistic Methods Applied to Power Systems, 2010.

[6] P. Dehghanian, M. Fotuhi-Firuzabad, S. Bagheri-Shouraki, et al.: "Critical component identification in reliability centered asset management of power distribution systems via fuzzy AHP”, IEEE Syst. J., 2012, 6, (4), pp. 593-602.

[7] A.D. Ashkezari, H. Ma, T.K. Saha, et al.: "Investigation of feature selection techniques for improving efficiency of power transformer condition assessment", IEEE Trans. Dielectr. Electr. Insul., 2014, 21, (2), pp. 836-844.

[8] J.C.M. Lucio, R.C.G. Teive, "Fuzzy causal maps for asset management: an approach for problem structuring and multi-criteria evaluation in electrical utilities". Proc. of IEEE PowerTech Conf., 2007.

[9] A. Ioannou, A. Angus, F. Brennan, (2017). Risk-based methods for sustainable energy system planning: A review. Renewable and Sustainable Energy Reviews, 74, 602-615. https://doi.org/10.1016/j.rser.2017.02.082.

[10] R. Syahputra, I. Robandi, M. Ashari, (2015). Performance Improvement of Radial Distribution Network with Distributed Generation Integration Using Extended Particle Swarm Optimization Algorithm. International Review of Electrical Engineering (IREE), 10(2). pp. 293-304.

[11] S. Khuntia, J. L. Rueda Torres, S. Bouwman, M. Van der Meijden, (2016). A literature survey on asset management in electrical power [transmission and distribution] system. International Transactions on Electrical Energy Systems, 26(10), 2123-2133. http://pure.tudelft.nl/ws/files/37133269/4744208_pp.pdf.

[12] http://www.instat.gov.al/en/themes/environment-and-energy/energy/.

[13] R. Bualoti, M. Çelo, The Situation and Development of Albanian Electric Power System in International Connection and Exchanges, SELIT Seminar on Electricity Interconnections Liberalization and Trade, Istanbul, Turkey, pp 31-34, September 18-20, 2001.

[14] L. Jalili, M.S. Khomami, M.F. Firozabad, (2011). Risk-based asset maintenance management in distribution system. 21st International Conference on Electricity Distribution. Frankfurt:6-9 June, CIRED 2011.

http://www.cired.net/publications/cired2011/part1/papers/CIRED201 1 1_0589 final.pdf.
[15] A. Paci, M. Celo, R. Bualoti, "Distribution System Reliability Indices. Case Study Albanian Distribution System", Journal of Multidisciplinary Engineering Science and Technology (JMEST) ISSN: 2458-9403 Vol.5 Issue 12, December-2018. pp.9137-9143. http://www.jmest.org/wp-content/uploads/JMESTN42352732.pdf.

[16] B.P. Lang and A. Pahwa, "Power distribution system reliability planning using a fuzzy knowledge-based approach," Power Delivery, IEEE Transactions on, vol. 15, pp. 279-284, 2000.

[17] A. Shokrollahi, H. Sangrody, M. Motalleb, M. Rezaeiahari, E. Foruzan, and F. Hassanzadeh, "Reliability Assessment of Distribution System Using Fuzzy Logic for Modelling of Transformer and Line Uncertainties," in 49th North American Power Symposium (NAPS), 2017, pp. 1-6.

[18] B. Behi, A. Arefi, H. Pezeshki, F. Shahnia, Distribution transformer lifetime analysis in the presence of demand response and rooftop PV integration, Renew. Energy Environ. Sustain. Vol.2, ID27 (2017), https://doi.org/10.1051/rees/2017013

[19] V.N. Pugach, D.A. Polyakov, K.I. Nikitin, I.L. Zakharov, N.N Petukhova, Analysis of Temperature Conditions Influence on Cables Insulation Operation Life, Journal of Physics: Conf. Series, Vol.1260 Issue 5, 2019. doi:10.1088/1742-6596/1260/5/052027.

[20] M. Çelo, R. Bualoti, M. Kullolli, Map with the Distribution of Originated Atmospheric Failure Indentified in the Albanian Power Transmition System and Calculation of Reliability Indeces, MEDPOWER'06, The 5th Mediterranean Conference \& Exhibition on Power Generation, Transmission and Distribution, Eilat, ISRAEL, November 15-17, 2006.

[21] Ch.S. Wasson, System Analysis, Design, and Development: Concepts, Principles, and Practices, chapter 50 "Reliability, Availability, and Maintainability", John Wiley \& Sons, 2005.

[22] J. Wang, J. Lu, Zh. Bie, Sh. You, X. Cao, "Long-Term Maintenance Scheduling of Smart Distribution System through a PSO-TS Algorithm", Journal of Applied Mathematics, Vol.2014, ID 694086, 12 pages, 2014.

[23] L. Simoni, A general phenomenological life model for insulating materials under combined stresses, IEEE Trans. Dielectr. Electr. Insul. 6, 250 (1999)

[24] J. W. Stahlhut, G. T. Heydt, and N. J. Selover, "A preliminary assessment of the impact of ambient temperature rise on distribution transformer loss of life," IEEE Transactions on Power Delivery, vol 23, no. 4, pp. 2000-2007, 2008.

[25] J. Ledezma, C. Dortolina, H. Hakelberg, K. Furuno, Condition Assessment and Asset Management in Electric Power T\&D Networks, Paper 0074, CIRED Workshop - Lyon, 7-8 June 2010.

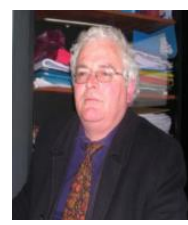

A. Paci received the Diploma in Electrical Engineering from the Tirana University, Albania, in 1996. After his studies, he worked in Albanian Power Corporation. From 2005 he joined the Technical Inspectorate, Tirana - Albania. He continues $\mathrm{PhD}$ study near Electric Power System Department, Electric Engineering Faculty of Polytechnic University of Tirana. The research interests include Power System Reliability Analysis, Distributed energy resources, Environmental impacts of power systems, Fuzzy Reasoning Approach, etc.

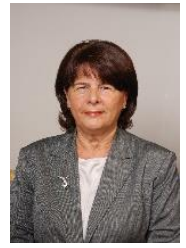

R. Bualoti received the Diploma in Electrical Engineering from the Tirana University, Albania, in 1981. From 1983 she joined the Electrical Engineering Faculty of the Tirana University. She received her $\mathrm{PhD}$ degree in 1989. Since 1999, she is Professor at Electric Power System Department, Electric Engineering Faculty of Polytechnic University of Tirana. The teaching and research interests include Transient Analysis in Electric Power System, Power System Stability and Control, FACTS, Fuzzy Reasoning Approach, Power System Reliability Analysis, Distributed energy resources, Smart grids, and intelligent use of energy, etc.

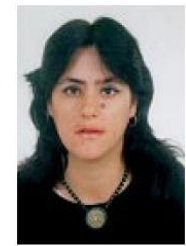

M.Çelo graduated in Electrical Engineering from Polytechnic University Tirana, Albania in 1990. She joint Albanian Power Corporation as a Project Engineer for Power Systems in 1991 and she had been engaged in the study, design, installation, maintenance, rehabilitation, and supervision of hydroelectric power plants, including system analysis, project appraisals, feasibility studies. She 
received PhD degree in Power System Reliability Analysis. Since 2014, she is Professor at Electric Power System Department, Electric Engineering Faculty of Polytechnic University of Tirana. The teaching and research interests include Network \& Power Systems Analysis, Energetic Economy, Power System Reliability Analysis, Distributed energy resources, Environmental impacts, demand response, forecasting pricing, etc. 